\title{
REFLEXÕES SOBRE AS CRENÇAS DE PROFESSORAS FORMADORAS DE LETRAS A RESPEITO DA COMPREENSÃO ORAL EM LÍNGUA INGLESA
}

\author{
Reflections on Teachers' beliefs about Teaching English Listening \\ Comprehension in a Language Graduation course
}

\author{
Clarita Gonçalves de CAMARGO \\ Universidade Federal do Paraná \\ clarita_camargo@yahoo.com.br \\ https://orcid.org/0000-0001-5641-3056 \\ Denise Cristina KLUGE \\ Universidade Federal do Paraná \\ deniseckluge@gmail.com \\ https://orcid.org/0000-0003-4656-7902
}

\begin{abstract}
RESUMO: Este estudo discute crenças de três professoras formadoras sobre conhecimentos necessários ao ensino da habilidade de compreensão oral na língua inglesa. Para isso, foram realizados entrevistas e um semestre de observação das aulas. O objetivo foi levantar as crenças e dialogar com as práticas no intuito de aprofundar informações que sejam relevantes no tratamento da referida habilidade. Esta é uma pesquisa qualitativa de base etnográfica que envolve docentes que atuam em cursos de Letras de duas instituições públicas de ensino superior. Os dados revelaram que o ensino da pronúncia é importante para melhorar a compreensão oral e que parece haver um modelo mais indicado em contexto de formação docente. Dá-se atenção também a importância dos aspectos gramaticais como preparação para a profissão. As diferenças entre os níveis de proficiência dos aprendizes foi fator de influência na abordagem das professoras, principalmente na manipulação de atividades voltadas à gramática e de valor semântico e pragmático da língua. A percepção de crenças conscientes foi observada devido ao conhecimento dessas professoras sobre a aprendizagem e sobre a importância da compreensão oral nesses espaços de ensino. PALAVRAS-CHAVE: Crença de professoras; Compreensão oral; Língua inglesa.
\end{abstract}

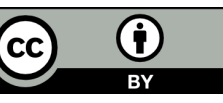




\begin{abstract}
This study discusses the beliefs of three teacher educators about the knowledge needed to teach oral comprehension skills. Thus, interviews and a semester of classes observation were carried out. The objective was to raise the beliefs and discuss them with the teachers' practices in order to deepen information about what is relevant in addressing the skill. This is a qualitative research with an ethnographic basis involving teachers who work in Language Graduation Course at the two public education institutions. The data revealed that the teaching of pronunciation is important to improve oral comprehension and that seems to be a more suitable model in the context of teacher training. Attention is also given to the importance of grammatical aspects as preparation for the profession. Differences in the learners' proficiency levels influence the teachers' approach, mainly with activities involving grammar as well as semantic and pragmatic aspects of the language. The perception of conscious beliefs was observed due to the knowledge of these teachers about learning and about the importance of oral comprehension in teaching. KEYWORDS: Teacher's beliefs; Listening comprehension; English language.
\end{abstract}

\title{
INTRODUÇÃO
}

A compreensão oral (CO) envolve a aprendizagem de muitos conhecimentos que incluem, principalmente, os aspectos da oralidade. Para desenvolver a aprendizagem, a abordagem por sub-habilidade ${ }^{1}$ remete ao treino de vários sub processos que atuam desde a percepção fonológica, passando pela ordem sintática e pelo nível semântico, até a compreensão semântica da mensagem (FIELD, 2008). Esses processos são vistos como competências iguais às que o indivíduo já usa em sua língua materna, mas devem ser aprimorados devido às restrições linguísticas encontradas em uma língua estrangeira. Pesquisadores como Field (2008) mencionam que o indivíduo tem que construir um conjunto de comandos linguísticos e cognitivos que deve ser trabalhado pelo professor em sala de aula. O problema é que não há muita clareza sobre as etapas de como isso deve ser ensinado.

Sendo assim, parece que a investigação em crenças de professores (BARCELOS, 1995, 2001, 2004; SILVA, 2001, 2007) pode trazer importantes informações para pensarmos na aprendizagem de $\mathrm{CO}$, a princípio na relação entre crença e prática. É importante destacarmos que o estudo em crenças precisa considerar o contexto e, neste artigo, olha-se também para as experiências anteriores do professor frente a aprendizagem.

\footnotetext{
${ }^{1}$ A abordagem por sub-habilidade refere-se ao treino de componentes da língua.

Revista X, v. 16, n. 5, p. 1379-1401, 2021.
} 
Os estudiosos em crenças são unânimes em afirmar sobre o reconhecimento da dimensão social que envolve esse assunto, uma vez que as crenças são "[...] situadas em um contexto social e formadas através de específicas instâncias de interação social [...]"2 (WOODS, 2003, p. 202). A relevância de investigar as crenças para entender as práticas é devido a entender que há uma relação mútua que sofre influência contextual.

É importante salientar que o presente estudo é parte de uma pesquisa de doutorado (2020) que investigou crenças em relação às abordagens dos professores sobre o ensino de compreensão oral na língua inglesa. Durante a pesquisa de doutorado, foi realizado também um estudo piloto (CAMARGO; KLUGE, 2019) com outras duas professoras formadoras, com o objetivo de testar e limitar os instrumentos de geração de dados. O estudo piloto foi fundamental para o desenho metodológico adotado para o estudo reportado neste artigo. Desta forma, este artigo objetiva discutir as crenças de três professoras formadoras de dois Cursos de Letras de duas instituições públicas de ensino superior sobre como deve ocorrer o tratamento do som, sobre como aspectos da compreensão oral devam ser ensinados e sobre como manipular/lidar com o insumo linguístico. Na sequência, serão apresentados breve considerações a respeito do estudo em crenças de professores, os caminhos metodológicos percorridos, bem como os resultados e a discussão desses a partir das orientações aos itens gramaticais e as instruções pedagógicas dado ao ensino da habilidade de compreensão oral na língua inglesa.

\section{BREVE CONSIDERAÇÕES A RESPEITO DO ESTUDO EM CRENÇAS DE PROFESSORES}

No Brasil, as primeiras pesquisas em crenças que envolviam o contexto de professores foram realizadas por volta da década de 90. O objetivo dessas pesquisas era levantar opiniões dos professores sobre dificuldades na aprendizagem, estratégia, motivação, atitudes de aprendizagem em sala, entre outros. Nessa época, algumas metodologias de investigação não levavam em consideração o contexto, ou seja, os dados muitas vezes eram analisados de forma isolada sem olhar para os fenômenos sociais que poderiam implicar em seus direcionamentos. Dessa forma, havia um levantamento quantitativo de informações, mas faltava um aprofundamento contextual que impossibilitasse explicar os fenômenos sociais que estavam implícitos, por exemplo.

Vários autores tiveram representatividade nessa época, podemos citar, por exemplo, Almeida Filho (1998), que não usou o termo crenças, mas o conceito de

\footnotetext{
${ }^{2}$ No original, em inglês: [...] situated in social context and formed through specific instances of social interaction [...] (tradução das autoras).
}

Revista X, v. 16, n. 5, p. 1379-1401, 2021. 
Abordagem ou Cultura de Aprender para investigar o processo de ensino e aprendizagem de inglês. Diferente da perspectiva anterior, essa já havia a intenção de olhar os fatores contextuais que entrelaçavam a prática de ensino, ou seja, fatores como crenças dos alunos, influências dos materiais didáticos, dos pais, dos diretores, entre outros, refletiam nas crenças dos professores e, por isso, deveriam ser analisados. Na década de 2000 o estudo em crenças continuava ganhando representatividade e um número expressivo de estudos, como Silva (2000, 2001, 2005, 2006, 2007), Conceição (2000), Barcelos (2004, 2006, 2007) entre outros muitos estudos, queriam aprofundar o entendimento sobre a relação do professor com a aprendizagem. Nessas pesquisas havia muitos direcionamentos que buscavam entender como as crenças eram formadas e quais relações elas estabelecem com o contexto, atribuindo a essas pesquisas um olhar etnográfico para as variadas situações vivenciadas em sala de aula. Dessa forma, esses estudos refletiam a tentativa de entender mais profundamente os espaços onde a aprendizagem acontecia. Para termos uma ideia, um levantamento feito em um artigo intitulado "Panorama da última década de pesquisas em crenças no Brasil: Reflexão no contexto de formação do professor de língua inglesa ${ }^{3}$ " constatou que entre os anos de 2008 e 2018 um total de 62 dissertações e oito teses utilizou o termo "crenças no ensino e aprendizagem de língua inglesa" com olhares para diferentes contextos- educação básica, na formação do professor e outros contextos. Entre os assuntos pesquisados está, em maior destaque, a abordagem do professor demostrando que as pesquisas continuam observando o professor e suas relações com a aprendizagem.

Para concluir, considerando as pesquisas recentes, observou-se que todas partem da abordagem qualitativa, envolvendo estudo etnográfico, estudo de caso, pesquisa ação, entre outros, levando em conta o contexto do participante. Os instrumentos de coleta de dados foram, em sua maioria, entrevistas, observações, notas de campo, entre outras maneiras de construir sentido para a complexidade que paira sobre o conceito de crenças. Além disso, notou-se que as perspectivas mais frequentes nas pesquisas partiam da relação entre crenças e ações, ou seja, observavam se existe dissonância ou não entre o dizer e o fazer docente e da relação entre crenças e experiências, na tentativa de entender o reflexo desse constructo para a formação da crença do professor.

A próxima seção apresentará os caminhos metodológicos da pesquisa deste artigo.

\footnotetext{
${ }^{3}$ Camargo, no prelo.

Revista X, v. 16, n. 5, p. 1379-1401, 2021.
} 


\section{CAMINHOS METODOLÓGICOS}

Durante o primeiro semestre do ano de 2018, as crenças de três de professoras universitárias foram levantadas por meio de entrevistas e observações ${ }^{4}$ realizadas durantes as aulas de língua inglesa no curso de graduação de Letras entre os meses de março e julho de 2018. A primeira professora, nomeada P1, é doutora em Linguística Aplicada e atua como docente há mais de 30 anos. A segunda professora (P2) é doutoranda em Letras e professora há mais de 20 anos. Por último, a terceira professora (P3) é doutora em tecnologia e docente há mais de 30 anos. As participantes P1 e P3 trabalham numa das universidades e a participante P2 em outra. Ambas as universidades estão localizadas no estado do Paraná. As pesquisadoras buscaram criar um diálogo entre as crenças relatadas nas entrevistas com as anotações realizadas durante as observações das aulas. Foram observadas 52 horas de aula da P1, 29 horas e 30 minutos da P2 e 85 horas da P3. Durante as observações foram feitas anotações. A abordagem escolhida, de base etnográfica ${ }^{5}$, permitiu aproximar as pesquisadoras com o ambiente de ensino, possibilitando que as crenças pudessem ser contextualizadas.

O desenvolvimento da investigação ocorreu por meio de quatro entrevistas semiestruturais individuais realizadas em língua materna com cada uma das professoras: uma no início do semestre, duas durante o semestre e uma no final do semestre acadêmico. Foi criado um diálogo entre as crenças relatadas nas entrevistas com as práticas observadas em sala, como forma de compreender com mais profundidade os discursos dos docentes sobre a aprendizagem. No período de geração de dados, as professoras desta pesquisa lecionaram inglês em disciplinas que consideravam diferentes níveis ${ }^{6}$ de proficiência: P1 lecionou uma disciplina do nível intermediário, P2 do nível avançado e P3 do básico.

\section{OS CONHECIMENTOS E PROCEDIMENTOS ESPECÍFICOS}

Ao observarmos as aulas, notamos que a participante P1 dava muita atenção ao ensino dos aspectos fonológicos da língua inglesa em atividades que envolvem $\mathrm{CO}$, por

\footnotetext{
${ }^{4}$ Esta pesquisa foi aprovada pelo Comitê de ética da UFPR e pelo colegiado de pós-graduação da mesma Instituição.

${ }^{5}$ Optou-se pela referência de Estudo de Caso (YIN, 2001).

${ }^{6}$ A parte da pesquisa que compõe este artigo, considera-se que o nível de conhecimento dos alunos teve impacto na abordagem do professor, por isso foi explicitado.

Revista X, v. 16, n. 5, p. 1379-1401, 2021. 
isso a questionamos acerca da preocupação desse tratamento como item necessário à compreensão da mensagem. Vejamos no seguinte discurso $\left(\mathrm{TRA}^{7}\right)$ :

\section{TRA1_Crenças sobre o ensino da pronúncia de (P1)}

A partir do momento que os alunos começam a conseguir entender e pronunciar os fonemas, eles passam a compreender quando expostos ao listenings [...]. Eu mostro maneiras de você pronunciar certos fonemas, mostro como é a cadeia da fala acontece, todos os links e todos os elipses, tudo direitinho, clusters, tudo. A partir disso, eles começam a compreender, a produzir [...] principalmente a compreender. (Entrevista 1)

Fonte: Dados da pesquisa.

Observa-se que a professora considera que o ensino da pronúncia em língua inglesa contribui para o desempenho da habilidade de $\mathrm{CO}$, e a partir das aulas observadas notou-se grande recorrência no tratamento da precisão da fala como pré-requisito para o desenvolvimento da oralidade, surgindo a necessidade de aprofundar essa questão. Vejamos a explicação de P1 sobre esse aspecto em TRA2.

\section{TRA2_Crenças sobre o papel da pronúncia no ensino da CO (P1)}

Entrevistadora: Gostaria que você me explicasse sobre o papel do ensino da pronúncia para a compreensão da mensagem?

Você traz a teoria da fonética e fonologia e faz a explicação, por que não? No listening ajuda muito, muito, quando eles conseguem fazer os clusters que nem loved (marcado ed). Eles entendem e fazem estes links, estes clusters todos. Na compreensão oral é muito legal. Eles começam a perceberem os ritmos; as entonações. Então, esta é a diferença de você advogar a favor da língua franca com responsabilidade. Você não pode advogar a língua franca para esconder a deficiência da fala ou da compreensão. Eu não espero que ninguém daqui saia um americano nativo. Não espero isso, é óbvio né, mas se eu consigo mostrar para eles como é que um americano, ou inglês faz [...]. É impressionante como eles começam a entender mais. Os alunos percebem que quando estão falando com não nativo, eles não fazem essa ligação, mas entendem. (Entrevista 2)

Fonte: Dados da pesquisa.

Observa-se que P1 defende que o ensino da pronúncia é um conhecimento importante que precisa ser desenvolvido, já que considera que a partir da percepção do som é que o indivíduo irá construir o significado da mensagem. O processo de compreensão

\footnotetext{
${ }^{7}$ TRA refere-se aos trechos das entrevistas.
} 
de uma palavra passa pelo acesso ao código fonético até o código semântico ou o nível do significado (ANULA REBOLLO, 1998). Isso é um dos motivos que impulsiona a atenção ao tratamento fonético e fonológico numa proposta com atividades de percepção (listening for perception) (UR, 1984). O treino da pronúncia pode beneficiar o ensino da compreensão oral porque quanto mais o aluno estiver exposto às diferentes amostras de uso, mais familiares serão as características da oralidade.

Nota-se também, no discurso reportado, que embora P1 apresente perspectivas da pronúncia num viés global, ela considera que o ensino da fala nativa não prejudica a compreensão quando os alunos estiverem em outros contextos. A professora, inclusive, critica a responsabilidade que o professor deve ter quando trata do conceito de língua franca $^{8}$. Para muitos professores a sala de aula deve adequar-se ao ensino formal da língua, mesmo que haja outras ocorrências. Então, parece que para a participante P1 a aprendizagem precisa obedecer a alguns padrões normativos da língua alvo, inclusive porque se trata da formação de professores. Vejamos mais crenças neste viés:

\section{TRA3_Crenças sobre o tratamento de conhecimentos específicos (P1)}

Pesquisadora: Então, para você o foco em alguns conhecimentos da língua ajuda na compreensão oral?

P1: Sim, precisa desenvolver inteligibilidade sobre o que eles estão fazendo ou falando e isso requer o tratamento de alguns conhecimentos específicos [...] (Entrevista 1)

Fonte: Dados da pesquisa.

Observamos que durante as aulas os conhecimentos relacionados ao tratamento do som eram recorrentes, o que pode indicar que P1 acredita que o treino da percepção da fala é importante para facilitar a compreensão, considerando que cabe ao professor ensinar explicitamente esse aspecto como uma maneira de diminuir futuras dificuldades como mostra o seguinte discurso:

\footnotetext{
${ }^{8}$ Língua Franca é entendida como a língua de contato, ou seja, uma língua que não pertence somente ao falante nativo. Para Jenkins (2011), uma das pesquisadoras da área do inglês como língua franca, esse termo considera que o sistema linguístico vem sendo adquirido pelos indivíduos de diversas nacionalidades que usam o inglês para se comunicar, desprendendo do padrão imposto somente pelo nativo. Nessa perspectiva, considera-se a língua pelo viés intercultural e, por isso, os falantes nativos e não nativos devem ajustar suas falas de acordo com as diversas situações comunicativas.
} 


\section{TRA4_Crenças no tratamento do som (P1)}

Pesquisadora: Então, você concorda que propor atividades que tenham a função de treinar certos conhecimentos da língua são importantes para o aprendizado?

Muito importante e eu faço sempre. Você viu hoje que na atividade de listening, eles não conseguiam entender um trecho porque eles não conseguiam entender o link da consoante com a vogal. Depois, eu mostrei como funciona essa conexão e eles entenderam. Eu voltei e fiz eles perceberem, então é boa a probabilidade de eles ouvirem e entenderem numa próxima vez. Então, sempre que surgem nos listenings atividades ou momentos específicos para desenvolver certas habilidades. Lembre-se a gente estava trabalhando meaning, mas por falta da percepção pontual, eles não entenderam o significado, então eu parei para trabalhar isso com eles [...]. Eu tenho muita preocupação de deixar contextualizado as coisas. (Entrevista 3)

Fonte: Dados da pesquisa.

Nota-se, no fragmento, que P1 usa bastante a metalinguagem para explicar componentes linguísticos, e muitos desses saberes vêm de algumas experiências anteriores reportadas aos seus alunos durantes as aulas. Ela tinha o costume de justificar algumas escolhas metodológicas dialogando com fatos de sua vida. Entende-se que é recorrente que as crenças dos professores recebam influências de experiências individuais externas à sala de aula (MICCOLI, 2010). Na primeira entrevista, P1 havia mencionado que a sua percepção em trabalhar o som da língua resultava de dificuldades pessoais, e esse trabalho lhe proporcionou um aprimoramento de conhecimentos nessa área. Foi observado em sala algumas técnicas para o trato de sons vibrantes, modos de articulações, de percepção auditiva etc., o que demonstrava a aptidão de P1 aptidão nesse aspecto. Esse conhecimento veio em parte construída pela experiência com profissionais em fonoaudiologia, conforme o discurso seguinte (TRA5):

\section{TRA5_Relação da crença e experiência no ensino da CO (P1)}

[...] Eu comecei a perceber que os exercícios que ele [o médico] fazia pra 'fono' me ajudava a aplicar aos meus alunos. Eu comecei a adaptar os exercícios para minhas aulas e foi muito interessante [...] porque a partir do momento que os alunos começavam a conseguir entender e pronunciar os fonemas, eles passam a compreender quando exposto a listening [...].

Fonte: Dados da pesquisa.

A participante $\mathrm{P} 1$, ao mencionar que mostra diferentes maneiras de pronunciar, demonstra novamente a crença de explicitar alguns componentes da língua alvo. $\mathrm{O}$ uso do ensino explícito para a conscientização das formas gramaticais pode trazer benefício 
ao aprendizado (ELLIS, 2003). Pode-se ainda constar que a compreensão e produção oral são habilidades que se assemelham no tratamento de aspectos da oralidade.

Por um lado, a crença sobre a pronúncia da fala nativa parece ser norteadora da aprendizagem. Por outro, P1 considera que o aluno precisa estar inserido em outras amostragens, como podemos observar no seguinte excerto:

\section{TRA6_Crenças sobre o uso da língua (P1)}

[...] você tem que levar para sala de aula situações nas quais os alunos são expostos ao listening, tanto de brasileiros falando, estrangeiros falando, nativos, expô-lo uma variedade de pessoas falando a língua estrangeira [...] (Entrevista 1).

Fonte: Dados da pesquisa.

A relação das crenças no tratamento da pronúncia estava dialogada por duas perspectivas, uma de um tratamento focado no nativo, o mais percebido nas práticas, e outro pela qual P1 considera, conforme o trecho acima (TRA6), que o aluno deve ser exposto a uma diversidade linguística, incluindo falantes nativos e não nativos da língua inglesa. Notando que essa segunda perspectiva não era muito enfatizada em sala, perguntamos à $\mathrm{P} 1$ o motivo e ela respondeu o seguinte:

\section{TRA7_Implicação de fatores contextuais nas crenças de (P1)}

Acho que não fiz muitas atividades. Eu não tenho tempo, eu tinha que ter tempo também para fazer o workbook, porque o workbook tem isso, têm estes listening dictation, de compreensão mesmo, que são importantes, mas eu não tenho tempo. Eu queria trabalhar mais os vários listenings e é impossível. Não dá tempo de dar conta de tudo [...] (Entrevista 2).

Fonte: Dados da pesquisa.

Nesse trecho, constatamos que fatores contextuais, como o currículo, impactam na prática do professor, inclusive na Universidade. Por outro lado, observa-se que a língua do nativo parece ainda ter grande representatividade na aprendizagem em sala de aula. Isso pode ser explicado porque muitos professores carregam concepções de língua e ensino de língua inglesa que foram muito propagadas pelas metodologias e abordagens ao longo dos anos, por isso essas amarras são difíceis de serem desprendidas totalmente. Nota-se que P1 mostra-se consciente da diversidade linguística entre falantes de diversas nacionalidades que usam o inglês, porém essa postura não foi percebida em suas práticas, embora justificada pela falta de tempo. Isso denota resistência de concepções mais Revista X, v. 16, n. 5, p. 1379-1401, 2021. 
recentes, a exemplo do que muitos autores chamam de inglês como língua internacional ou língua franca. As atividades de $\mathrm{CO}$ podem estimular o aluno a encontrar as mesmas palavras em uma variedade de contextos e vozes, o que pode ser desenvolvida pelo professor (FIELD, 2008).

Passando a analisar as falas da participante P2, notamos crenças de que o tratamento dos itens específicos da língua deve ocorrer a partir das dificuldades dos alunos, ou seja, os problemas de aprendizagem devem ser identificados pelo professor para, então, desenvolver um trabalho direcionado, conforme nota-se:

\section{TRA8_Crenças em trabalhar conhecimentos específicos da língua (P2)}

Eu acho que você tem que trabalhar alguns aspectos separados, não só de listening, mas de gramática mesmo [...]. Nas aulas, você deve perceber as dificuldades e trazer os itens para trabalhar com eles para que eles melhorem. Não trazer o currículo pronto, mas o que aparece em sala de aula. (Entrevista 1)

Fonte: Dados da pesquisa.

Essa postura de que os conhecimentos linguísticos da oralidade devem ser ensinados a partir dos problemas enfrentados pelos alunos corrobora as ideias de muitos autores que estudam CO, inclusive Field (2008), uma vez que os erros de compreensão ou dificuldades devam ser identificados e, posteriormente, manipulados em atividades direcionadas. A participante P2 apresenta essa crença e também menciona que cabe ao próprio aluno trabalhar seus problemas de compreensão oral, dialogando com as perspectivas da abordagem por processos (process approach), já que muitos problemas de entendimento podem ser diminuídos se os alunos estiverem conscientes das etapas de aprendizagem (NUNAN, 1997). Nota-se na fala seguinte que a compreensão oral é uma habilidade individual no que se refere às etapas envolvidas, conforme também defende Field (2008).

\section{TRA9_Crenças sobre a manipulação do insumo (P2)}

Para compreensão oral eles têm que acompanhar uma sequência de capítulos curtos para ver o que eles estão conseguindo compreender e voltar várias vezes quando tiverem dificuldades [...] (Entrevista 3)

Fonte: Dados da pesquisa. 
Fica evidente que a professora considera que o aluno deve adotar uma postura mais autônoma na aprendizagem, mas isso irá depender de fatores como motivação, interesse ou até mesmo um perfil mais autodidata, o que nem sempre ocorre entre os aprendizes, mesmo os universitários. Ao tentarmos aprofundar alguns conhecimentos necessários à $\mathrm{CO}$, notou-se que $\mathrm{P} 2$ acredita que pelo fato de os alunos estarem em nível avançado sua abordagem irá propor práticas que contenham variedades de insumos linguísticos, cujos propósitos são o de aperfeiçoar a fluência oral, já que P2 considera que seus alunos já possuem um bom conhecimento linguístico da língua inglesa, conforme a participante demonstra na sequência (TRA10). Field (2008), nesse sentido, orienta que a função da prática nesse contexto é a de aprimorar a habilidade comunicativa.

\section{TRA10_Crenças sobre o ensino específico de CO (P2)}

Entrevistadora: Como você percebe o ensino da compreensão e produção oral nos seus alunos? P2: Nesta turma eu não tenho aluno com problemas de compreensão porque eles são muito fluentes. Eu digo a eles [...] escolha um seriado e assista com legenda, com tradução e depois sem tradução. Repita várias vezes até que vai melhorando [alunos de outros contextos]. Aqui, em sala com quinze, não dá para fazer muito, mas eu faço muita atividade em grupo. Eu acho que no grupo eles se expõem melhor sem muita exposição. [...] (Entrevista 2)

Fonte: Dados da pesquisa.

Observamos nas aulas da professora P2 que houve várias propostas de atividades em grupos para prática com a oralidade e, embora, os alunos conversassem sobre vários temas, não apresentavam problemas com as habilidades de compreensão e produção oral em língua inglesa. Isso contribuiu para a baixa intervenção do professor em sala de aula. Os insumos linguísticos (oral e escrito) tinham a função de proporcionar uma prática discursiva de forma espontânea, através de diálogos ou por questões preestabelecidas. Essas atividades levavam a problematizar questões do convívio social, favorecendo perceber uma visão de ensino apoiado nas perspectivas do letramento crítico. Foi importante notar que P2 observava o comportamento comunicativo dos alunos para, então, realizar as mediações, o que corrobora em dar sentido à aprendizagem (FIELD, 2008).

Retomando o trecho discutido, nota-se também que alguns procedimentos metodológicos como "assista com legenda", "com tradução", "sem tradução" indicam crenças de como deve ser a aprendizagem em níveis mais iniciantes; ou seja, para P2 a compreensão oral exige a prática de repetição do áudio para manipular a estrutura linguística até o encontro com o significado. Esse procedimento atribui ao aluno maior 
responsabilidade com suas falhas de compreensão, colocando o professor no papel de colaborador. Vejamos abaixo mais crenças reportadas pela participante P2:

\section{TRA11_Crenças sobre abordagem de ensino de CO (P2)}

P2: Eu coloco o áudio para tocar duas vezes e vejo se eles entenderam. Para o muito básico eu colocava o script para eles acompanharem o texto escrito junto, porque eu acho que é assim que os alunos começam a perceber mais. Nossa, foi isso que ele disse, e começa a se familiarizar com aquele discurso. Vão percebendo o ritmo da fala, a entonação, como é a junção das palavras, como ocorre a contração das palavras. E, essa percepção faz com que eles percebam as coisas aparentemente inaudível [...] (Entrevista 3)

Fonte: Dados da pesquisa.

Nota-se nesse trecho crenças de que aspectos linguísticos são percebidos no momento da exposição à prática, sem que, necessariamente, o professor deva ater-se a um conteúdo específico. A estratégia de usar a transcrição em alunos iniciantes dialoga com as orientações teóricas de que as elisões, assimilações e outras variações da oralidade, quando percebidas, podem contribuir para diminuir problemas com futuras exposições à prática (FIELD, 2008). Para P2, a participação do aluno à oralidade parece ser condição necessária para a melhora do desempenho na língua alvo.

Por sua vez, é importante mencionar que o fato de P2 não sofrer a imposição de adotar um livro pedagógico ou um currículo preestabelecido parece contribuir para um ensino mais voltado às necessidades da sala de aula. Aspectos específicos da oralidade eram abordados de forma espontânea quando ocorridos na interação. Essa postura conversa com o ensino comunicativo de que as atividades devem priorizar o foco no significado pragmático da língua (XAVIER, 2012).

Passando a análise para a professora denominada P3, foram frequentemente observados exercícios focados no ensino da pronúncia - sentence stress, words stress, entre outros. Essas atividades eram modelos adotados do livro didático que traziam para esse ensino amostragens do inglês britânico e americano, porém a professora fazia um alerta de que havia outras variedades de fala, nos motivando a perguntarmos sua opinião sobre qual é sua postura em lidar com aspectos de pronúncia em sala de aula.

\section{TRA12_Crenças sobre aspectos da pronúncia (P3)}

Entrevistadora: Percebi que você traz a perspectiva de que há uma língua menos engessada pelo falante nativo, mas ainda alguns procedimentos metodológicos contemplam esse falante. Como você procura lidar com isso? 
P3: Eu acho que os livros já estão fazendo isso. Eu acho que com os jogos isso também ocorre, porque eles conversam com não nativos em inglês. O ideal é variar com os não nativos, mas a gente expõe os alunos e quer uma pronúncia correta. O problema é que na vida real não é bem assim, mas não tem como ensinar com toda esta variedade. É muita coisa, por isso precisa se espelhar no nativo. (Entrevista 3)

Fonte: Dados da pesquisa.

O discurso mostra que embora a professora esteja mais consciente das variedades de sotaque que envolvem os usuários de inglês, ainda sente dificuldades em trabalhar isso. Para muitos professores, os estudantes devem preocupar-se mais com os ajustes da pronúncia como forma de minimizar as dificuldades de compreensão do que pensar em estratégias comunicativas, como lidar com a negociação de significado, por exemplo (OXFORD, 2001). Na sala de aula, a professora oferecia alguns momentos de feedback referentes à produção da fala, mas não de forma recorrente. Já na compreensão oral, os áudios trazidos pelo gravador eram colocados para prática de repetição, o que também favorecia um modelo padrão, mas com discurso facilitado, conforme observado pela professora:

\section{TRA13_Crenças no insumo facilitado ancorado pela abordagem do livro (P3)}

P3: Então, essa questão do listening eu acabo usando o que está no livro. Eu acabo percebendo que alguns listening fica facilitado, meio controlado e não muito natural. (Entrevista 2)

Fonte: Dados da pesquisa.

Nota-se que P3 usa frequentemente as atividades do livro que apresenta o ensino de pronúncia no formato: "ouvir e preencher lacunas", “ouvir e repetir", “ouvir e identificar", “ouvir e selecionar", entre outras. O ensino do vocabulário também foi percebido em atividades de CO. Alguns aspectos da gramática que apareciam nos áudios, como o som da forma verbal “-ed, did, didn't", a entonação das palavras, os ritmos e o uso de marcadores discursivos eram explicitamente ensinados pela professora. Para P3, parece que o ensino da língua necessita de um conhecimento linguístico que tem relação com as normas internas da gramática (TRA14). 


\section{TRA14_Crenças sobre o tratamento linguístico (P3)}

P3: O ensino precisa de um equilíbrio. Embora, haja necessidade de usar a língua para se comunicar, sem gramática não tem como a pessoa se comunicar, não dá para falar de qualquer maneira porque ninguém vai compreender (Entrevista 2)

Fonte: Dados da pesquisa.

Nota-se que a professora, ao mencionar que "não dá para falar de qualquer maneira porque ninguém vai compreender", mostra que a compreensão e produção oral devem adequar-se à norma linguística, desconsiderando possíveis variedades de fala. Isso é comum pois muitos professores acreditam que há um modelo correto de padrão linguístico e que cabe ao professor ensiná-lo. Em suma, o trato com os itens linguísticos ocorria orientado por uma abordagem mais estrutural, o que era ensinado explicitamente. Essa preocupação é novamente influenciada pelo contexto de formação do professor, que exige, segundo ela, atenção ao ensino das normas gramaticais. Vejamos:

\section{TRA15_Crenças sobre o foco na forma (P3)}

P3: A pessoa tem que entender por traz do que ela está falando. O aluno precisa de uma estrutura básica e o professor precisa ensinar. O contexto de futuros professores vai exigir que eles aprendam a gramática. (Entrevista 2)

Fonte: Dados da pesquisa.

É notável que P3 considera que a turma de formação docente tem impacto na abordagem do ensino à gramática, mas ela também considera que esse conhecimento é importante para desenvolver fluência. Trabalhar aspectos linguísticos mesmo dentro de uma proposta comunicativa ainda parece envolver resquícios de uma abordagem mais estrutural, o que também foi percebido nas aulas da professora. A turma de iniciantes favorece o tratamento mais recorrente de aspectos gramaticais, uma vez que esses aprendizes foram menos expostos à língua alvo e, portanto, têm menos exemplos de estruturas que os auxiliem na compreensão oral.

A nosso ver, de forma geral, notou-se que as três professoras tiveram diferentes crenças e abordagens, motivadas por diversas influências, inclusive pelo ambiente da sala de aula. Nas aulas de P1, os alunos (nível intermediário) eram mais participativos, o que proporcionava mais práticas dialogadas no sentido de interagir com o insumo, negociar significados e compartilhar informações referentes aos conhecimentos linguísticos. 
Na sala de P2, os alunos (nível avançado) mostravam-se fluentes, o que proporcionou aprofundamento aos temas abordados, sem necessidade de tratamento das regras. Por último, a turma (nível básico) de $\mathrm{P} 3$ tinha problemas relacionados à motivação e pouco conhecimento linguístico, o que impulsionava atividades mais focadas no conteúdo estrutural do que na interação.

Dessa forma, é notável que o perfil dos alunos teve influência na abordagem de ensinar do professor, conforme já alertado por Almeida Filho (1998). A preocupação com aspectos linguísticos recai principalmente nos aspectos de pronúncia, atribuindo à $\mathrm{CO}$ também uma habilidade importante para o trato nesse aspecto.

\section{A PRÁTICA DE ENSINO}

Ao observarmos as práticas de $\mathrm{P} 1$, verificamos que o foco no vocabulário e na pronúncia em atividades de compreensão oral foram recorrentes como em práticas de percepção do som, identificação e similaridade, formas contrastivas, regras de padrões de entonação e tonicidade das palavras. A aplicação do insumo com foco na forma (aspectos linguísticos) ocorre com atividades de intensive listening que, segundo Dekeyser (1998, p. 51), são "exercícios mecânicos e padronizados" que "podem ser úteis para se estabelecer uma relação entre formas linguísticas (para umas regras fonológicas e morfológicas)". Vejamos trechos das práticas de ensino (TPE).

\section{TPE1_Prática com foco na forma (P1)}

Take a look people, now we are going to listen to some sports (...) we open our book (pg. 24), now we listen to some people talking about sports than we have to listen and complete the gap with phrasal verbs [...] what sports? Ok. Do you understand? Right?

(Trecho da aula em 07/03/2018).

Fonte: Dados da pesquisa

Esses modelos de exercícios com foco no vocabulário como em TPE1 ocorreram várias vezes e são modelos trazidos pelo livro didático contendo atividades com: sentence/ word stress, stressed syllable, intonations e rhythmic patterns. A CO para percepção (listening for perception) tem por objetivo direcionar a atenção do aprendiz para o som da língua (UR, 1984). Ao propor essas atividades, P1 usa estratégias de repetição do som e conscientização das regras fonológicas sobre os aspectos de pronúncia. Essas propostas ainda envolvem aspectos da língua padrão, não se atendo em nenhum momento a uma 
explicação de língua por um viés global, ou alguma perspectiva de pronúncia como língua internacional. Vejamos mais um exemplo de prática de ensino:

\section{TPE2_Prática com foco na pronúncia (P1)}

We need to have a good pronunciation, repeat the horse, horseback, horseback riding. I don't understand, horseback riding”, horseback riding (prática de repetição enfatizando a pronúncia) $[\ldots]$

P1: repeat I like watching $T V$ (prática de repetição)

P1: I like working (prática de repetição)

P1: Look 'mm', 'I'

(P1 enfatiza a pronúncia, explicando aspectos fonológicos das diferenças das pronúncias quando seguidas de vogais ou consoantes (voiced/unvoiced sons). (Transcrição da aula em 07/03/18)

Fonte: Dados da pesquisa.

Nota-se que o insumo para repetição e algumas atividades de drills retomam em alguns momentos a abordagem estruturalista em que o aluno precisava memorizar certos aspectos linguísticos. É importante ressalvar que essa abordagem ocorria em momentos distintos, não atribuindo a P1 uma visão mecanicista de aprendizagem. Para Ur (1994), a repetição é um exercício útil para o treino da articulação da pronúncia em que os alunos ao repetirem conseguem perceber as diferenças entre forma escrita e oral. Nota-se também que P1 considera o ensino explícito importante para a aprendizagem, inclusive ao manipular práticas numa abordagem metalinguística. É importante mencionar que ainda não há uma conclusão que indique quais das abordagens (explícitas ou implícitas) são mais favoráveis (XAVIER, 2012).

O uso do áudio com o objetivo de percepção do som, identificação de palavras e expressões foi o que mais marcou no tratamento dos itens linguísticos direcionados à compreensão auditiva, portanto, explicitações sobre o trato fonológico têm um papel importante na aprendizagem para P1. Vejamos TPE3:

\section{TPE3_Prática no ensino explícito (P1)}

Fragmento 1

(Professora coloca um áudio contendo palavras para repetição e após explica a regra de pronúncia)

P1: How do we pronounce? 'Adjective' (professora escreve no quadro (/'æ.ḑ̧ık.tıv/).

P1: Repeat! (prática de repetição)

$\mathrm{P} 1$ : Why do we pronounce this form? (P1 repete a palavra).

$[\ldots]$

P1: Remember in Portuguese language, that is basically the 'oxitona, proparoxitona' [...]

(P1 explica a diferença da acentuação em português e em inglês, exemplificando no quadro)

Revista X, v. 16, n. 5, p. 1379-1401, 2021. 
P1: In English it is frequent because we put the accent in the second syllable [...]

P1: Now we are going to listen and underline the stressed syllable in these multi syllable adjectives. Listen and check.

(Transcrição da aula em 14/03/18)

Fragmento 2

(P1 coloca um áudio)

Gravação: This is a mother

This is a father

This is a brother

(P1 repete as palavras e mostra onde acontece o ponto de articulação e algumas regras fonéticas da língua)

P1: We need to use vocal cords vibration [...]

P1: You will become a teacher and you need to have a good pronunciation. Do you understand?

(Transcrição da aula em 05/03/18)

Fonte: Dados da pesquisa.

Fica evidente nos fragmentos mostrados que as atividades de $\mathrm{CO}$ têm objetivo também de trabalhar com os sons da língua. Inclusive, a professora explica regras de fonética. Segundo a professora, essa abordagem metalinguística também é justificada pelo contexto, que envolve a formação docente. Durante as observações havia bastante ênfase nesse aspecto. No levantamento de suas crenças, P1 havia mencionado: "Eu não espero que ninguém daqui saia um americano nativo, não espero isso, é óbvio, né, mas se eu consigo mostrar para eles como é que um americano ou inglês faz”. Depois conclui: "os alunos percebem que quando não estão falando com não nativo, eles percebem que eles não fazem essa ligação, mas entendem” (Entrevista 2). Essa fala demonstra que P1 acredita que o ensino da pronúncia nativa não prejudica o contato com o não nativo, mas essa é uma visão que, de certa forma, pode estar "favorecendo a crença de que existem pronúncias superiores" e estereótipos de prestígios (BARBOSA, 2007, p. 43).

$\mathrm{Na}$ sequência, encontramos um exemplo de prática que tem por objetivo relacionar a pronúncia com o significado (TPE4):

\section{TPE4_Prática de repetição com foco na forma (P1)}

P1: Repeat dessert and desert (alunos repetem).

P1: What do you eat?

Students: Dessert.

[...]

P1: Look, the stress is different. Pay attention in your pronunciations. This is important for people to understand [...] (Transcrição da aula em 14/05/18)

Fonte: Dados da pesquisa. 
Observamos ainda que essas atividades atingiam o foco semântico com objetivo de conscientização fonológica. Havia também a manipulação do áudio de forma pausada para associar o som ao significado. Algumas estratégias de memorização direcionavam a atenção do aluno a determinados comportamentos linguísticos, principalmente aqueles contendo traços da oralidade. Neste aspecto, concordamos com Almeida Filho e El Dash (2002, p.18) de que "[as] atividades de compreensão devem explorar os vários aspectos de textos orais, desde os sons até as interpretações mais complexas".

Por sua vez, foi notado que $\mathrm{P} 1$, ao ensinar aspectos gramaticais, também adotava uma prática reflexiva sobre o processo, levando os alunos a refletir sobre o motivo de determinadas escolhas metodológicas. Vejamos mais um trecho da aula (TPE5).

\section{TPE5_Prática sobre a abordagem reflexiva com foco na forma (P1)}

$\mathrm{P} 1$ When we are listening, we are learning the past perfect; we need to listen the past perfect in context. How do we pronounce the past perfect? [...] in the second time, we have to use dictation for listening. Você acha que dictation é uma coisa ultrapassada? Não, depends on how you use it, when you use it, why did you use? [...] you need to try to identify the sounds [...]. (Transcrição da aula em 28/03/18)

Fonte: Dados da pesquisa.

A construção reflexiva sobre a aprendizagem também recai no tipo de abordagem adotada pelo professor. Em um curso de Letras, a orientação entre teoria e prática faz muito sentido para a formação docente. No discurso acima, ela reporta procedimentos pedagógicos que possibilita ao aluno a pensar nos procedimentos de aprendizagem. No próximo fragmento, trazemos mais um exemplo de prática reflexiva.

\section{TPE6_Prática reflexiva sobre foco na forma (P1)}

P1: You need to teach the grammar with the context, how we use it, when you use it, you never teach the grammar for the grammar, we need to put it in the context. [...] you connect the grammar, vocabulary in order with the situation [...] You remember local, global, local, a partir da situação eu vou dialogar com os gêneros. (Transcrição da aula em 19/03/18)

Fonte: Dados da pesquisa.

Por fim, conclui-se que a CO nas aulas da participante P1 tinha a função de trabalhar a pronúncia, o vocabulário e algumas estruturas da língua como did/didn't, phrasal verbs, (have/had), entre outras. O propósito dessa prática era discriminar sons, 
identificar a palavra, reconhecer a estrutura correta e aspectos prosódicos, perceber acentuação, entonação, entre outros, atribuindo a CO o papel também de manipular esses aspectos linguísticos.

Com base nas aulas da professora P2, não foram encontradas atividades direcionadas ao foco na forma (itens linguísticos) que contemplassem a $\mathrm{CO}$ e nem outras habilidades comunicativas, por isso não houve dados que pudessem ser analisados.

$\mathrm{Na}$ análise da informante $\mathrm{P}$, foi observado que a professora seguia estas etapas: primeiro ela explicava o conteúdo explicitamente; na sequência, reproduzia o áudio para percepção da forma (item gramatical) e depois usava esse conteúdo para prática de conversação. Vejamos um exemplo de ensino explícito (TPE7).

\section{TPE7_Prática ensino explícito com foco na forma (P3)}

(Professora ensina explicitamente na lousa como funciona o uso de "there is" e "there are") P3: Guys, we use 'there is' when we need to indicate something in the place [...] the difference between 'there is' and 'there are' is that one is singular and the other is plural. How do we use there is and there are in negative and interrogative sentences? Look [...] (Transcrição da aula em 04/04/2018)

Fonte: Dados da pesquisa.

O ensino explícito ocorria antes da exposição do aluno à oralidade, o que acontece em muitos contextos de aprendizagem. Para Zhang (2009, p. 185), há falsas ideias de que com a abordagem comunicativa todo o ensino da gramática é adquirido implicitamente. Para o autor, o ensino da gramática pode incorporar "forma, significado e uso". Nesse sentido, compreende-se que a aprendizagem para P3 depende de atividades no enfoque de aspectos estruturais, como também momentos de exposição à regra de forma explícita.

Na sequência, nota-se outro fragmento do uso do áudio com objetivo do foco na forma.

\section{TPE8_Prática no uso do áudio para foco na forma (P3)}

P3: [...] We are going to listen and we repeat the sentences. Use there is or there are.

(áudio 1): There is no TV. (pausa e repetição)

(áudio 2): There isn't a remote control (pausa e repetição)

(áudio 3): Is there a ghost?(pausa e repetição)

[...]

(Transcrição da aula em 04/04/2018)

Fonte: Dados da pesquisa. 
O uso do áudio para atividades com foco na percepção do som é comum em atividades de $\mathrm{CO}$. Essa proposta familiariza o aluno a perceber o comportamento linguístico em contexto de uso, o que com a repetição pode contribuir para fixação. Essa prática não coloca o aluno na interação social, por isso P3, na sequência, propõe a prática de exposição à oralidade mostrada (TPE9)

TPE9_Prática comunicativa com uso controlado pelo foco na forma (P3)

P3: Ok. People. (Professora chama uma aluna e pergunta)

$\mathrm{P} 3$ : What is there in your dining room?

Estudante 1: What is [...] (aluna não consegue completar a frase)

P3: What is there in dining room? Repeat dining room.

ST1: Dining room.(estudante não responde porque parece não entender)

P3: Let me show you. Look at the book. Take a look a picture here. Remember you need to study the vocabulary [...]

[...]

P3: Are there two chair in your dining room?

Estudante 2: No, there aren't. There are four.

[...]. (Transcrição da aula em 04/04/2018)

Fonte: Dados da pesquisa.

Notamos que os diálogos de P1 são correspondentes ao conteúdo ensinado, favorecendo perceber que o ensino deve condizer com as etapas de aprendizagem. Nesse trecho o foco da forma veio antes do foco no significado. Essa maneira de trabalhar tem relação com crenças de P3 sobre a importância do tratamento da gramática como prérequisito para oralidade, conforme já levantados nas seções anteriores.

Para encerrar, conclui-se que P1 e P3 direcionam a CO com foco na forma, mas numa abordagem diferente. A participante P1 manipula o trato dos itens linguísticos conforme as ocorrências, já P3 o faz de acordo com o conteúdo ensinado. Ambas usam o áudio para percepção do som e foco no vocabulário. $\mathrm{O}$ ensino explícito também é frequente, mas $\mathrm{P} 1$ dá ênfase à abordagem reflexiva sobre os componentes linguísticos. Por último, P2 não direciona a atenção aos itens linguísticos e foca em trabalhar a parte semântica e pragmática da língua.

\section{CONSIDERAÇÕES FINAIS}

A partir da análise pode-se perceber crenças no ensino da pronúncia em atividades de $\mathrm{CO}$, podendo ser compreendido como um conhecimento necessário à aprendizagem. Ficou evidente também que há indicações de um padrão de pronúncia quando é ensinado Revista X, v. 16, n. 5, p. 1379-1401, 2021. 
em ambiente escolar, principalmente no que se refere à formação docente em Letras. Olhando para os dados, pode-se afirmar, ainda, que o contexto influenciou as crenças dos professores inclusive para uma abordagem metalinguística em níveis mais iniciantes e a não focada em itens específicos da oralidade em nível avançado. Aspectos formais da língua não foram retratados pela professora (P2) que atua com alunos fluentes, demonstrando priorizar o discurso construído socialmente. Outro aspecto notado foi a influência do material didático nas atividades de duas professoras, constatando que a abordagem desse instrumente tem impacto na aprendizagem de $\mathrm{CO}$, inclusive no tratamento de itens específicos da língua.

Podemos afirmar que o nosso objetivo de olhar as experiências das professoras também trouxe dados importantes para compreender a abordagem adotada em $\mathrm{CO}$, porque proporcionou entender algumas implicações pedagógicas: sobre o conhecimento de P1 no trato de aspectos fonológicos, sobre a perspectiva de Letramento na manipulação do insumo linguístico de P2 e sobre o tratamento mais formal de aspectos linguísticos de P3, por exemplo. As professoras também tiveram crenças conscientes que foram justificadas em suas práticas, demonstrando que o professor, nesse contexto, tem conhecimento capaz de justificar suas escolhas. Podemos afirmar que, nesse cenário, as professoras demonstraram estar cientes de suas crenças e dos problemas enfrentados em sala de aula, evidenciando que o currículo e o contexto impactam nessa relação. Para Barcelos (2001, p. 86), é importante "abrir a discussão a respeito das crenças" para tomada da consciência sobre suas influências nas práticas. Esse aspecto foi observado na pesquisa.

Para finalizar, destaca-se que tanto as crenças levantadas no estudo piloto quanto às discutidas neste artigo tiveram forte influência contextual e, além disso, demonstraram ser reflexos das experiências anteriores dos professores sobre a aprendizagem, oportunizando pensar o quanto que esses fatores implicam na aprendizagem.

\section{REFERÊNCIAS}

ALMEIDA FILHO; J. C. P. Dimensões comunicativas no ensino de língua. Campinas, SP: Pontes, 1998.

; EL DASH. L.G. Compreensão da linguagem oral no ensino de língua estrangeira. Revista de Linguística Aplicada, UNB, v.1, n.1, p.19-37, Brasília, 2002.

ANUla REBOllo, A. EL abecé de la Psicolinguística. Madrid: Libros, 1998.

BARBOSA, A. R. J. A abordagem do professor de inglês em relação aos "erros" de pronúncia dos aprendizes. 2007. 206f. (Doutorado em Linguística) Universidade 
Federal do Ceará, Ceará, 2007.

BARCELOS, A. M. F. Metodologia de pesquisa das crenças sobre aprendizagem de línguas: Estudo da arte. Revista brasileira de linguística aplicada, v.1n.1, 71-92, 2001

; Metodologia de pesquisa das crenças sobre aprendizagem de línguas: Estudo da arte. Revista brasileira de linguística aplicada, v.1n.1,71-92, 2001.

Crenças sobre aprendizagem de línguas, linguística aplicada e ensino de línguas. Linguagem \& Ensino, Pelotas, v. 7, n. 1, p. 123-156, 2004.

Cognição de professores e alunos: tendências recentes na pesquisa decrenças sobre ensino e aprendizagem de línguas. In: e Vieira Abrahão, M. H. (Orgs.). Crenças e Ensino de Línguas: foco no professor, no aluno e na formação deprofessores. Campinas: Pontes,p. 15-42, 2006.

. Narrativas, crenças e experiências de aprender inglês. Linguagem \& Ensino, v. 9, n. 2, p. 145-175, jul. /dez. 2007.

CAMARGO, C. G. Crenças e práticas de professoras formadoras sobre o ensino da compreensão oral em língua inglesa. Tese de doutorado em Letras apresentada à Universidade Federal do Paraná (UFPR), Curitiba, 2020.

; Panorama da última década de pesquisas em crenças no Brasil: Reflexão no contexto de formação do professor de língua inglesa. No prelo.

; KLUGE, D.C. Crenças de duas professoras de um curso de Letras a respeito das abordagens de ensino da habilidade de compreensão oral em língua inglesa. Revista Caletroscópio, Linguística Aplicada, vol. 7, n.1, 2019.

CONCEIÇÃO, M. P. Vocabulário e consulta ao dicionário: analisando as relações entre experiências, crenças e ações na aprendizagem de LE. Dissertação (Mestrado em Estudos Linguísticos) - Faculdade de Letras, Universidade Federal de Minas Gerais, Belo Horizonte, 2000.

DEKEYSER, R. Beyound focus on form: Cognitive perspective on learning and practicing second language grammar. In DOUGHTY, C; WILLIANS, J. Focus on form in classroom language acquisition. New York: Cambridge University Press, 1998.

ELLIS, R. Task-based language learning and teaching. Oxford: OUP, 2003.

FIELD, J. Listening in the language classroom. Cambridge: Cambridge University Press, 2008. 
MICCOLI, L. Experiências, crenças e ações: uma relação estreita na sala de aula de LE. In: SILVA, K. A. (Org.) Crenças, Discursos e Linguagem. Volume I. Campinas: Pontes, p. 135-165, 2010.

NUNAN, D. Approaches to Teaching Listening in the Language Classroom. Tesol conference. P. 1-10, 1997.

OXFORD, R. L. Language learning strategies: what every teacher should know. Boston: Heinle \& Heinle, 2001.

SILVA, L. O. Crenças sobre aprendizagem de língua estrangeira de alunos formandos de Letras: um estudo comparativo. Dissertação de Mestrado em Linguística Aplicada, Faculdade de Letras, UFMG, Belo Horizonte, 2001.

Crenças e aglomerados de crenças de alunos ingressantes em Letras (Inglês). Dissertação (Mestrado em Linguística Aplicada), Instituto de Estudos da Linguagem, UNICAMP, Campinas, 2005.

O Futuro Professor de Língua Inglesa no Espelho: Crenças e Aglomerados de Crenças na Formação Inicial. In Crenças no ensino de línguas. Foco no professor, no aluno e na formação de professores. Editora Pontes, Campinas, São Paulo, 2006

SILVA; A. K. Crenças sobre o ensino e a aprendizagem de línguas na linguística aplicada: um panorama histórico dos estudos realizados no contexto brasileiro. Linguagem \& Ensino, v.10,n.1,p.235-271,jan./jun.2007

UR, P. Teaching Listening Comprehension. Cambridge, Cambridge University Press, 1984.

XAVIER, R. P. 6 Período Metodologia do Ensino do Inglês. Copyright, 2012.

ZHANG, J. Necessity of Grammar Teaching. International Education Studies. V.2, N.2, 2009.

WOODS, D. The social construction of beliefs in the language classroom. In: KALAJA; P; BARCELOS. A. M. F. (Ed.). Beliefs about SLA: New Research Approaches. Dordrecht: Kluwer, p. 201-229, 2003.

YIN, R. Estudo de caso: planejamento e métodos. 3. ed. Porto Alegre, Bookman, 2001. 